\title{
A GESTÃO DO ENSINO SUPERIOR EM XEQUE
}

\section{Higher Education In Dire Straits}

\author{
Guilherme Marback Neto ${ }^{1}$
}

\section{Resumo}

O ensino superior brasileiro está em xeque porque dele se exige que apresente qualidade, cresça em quantidade e seja auto-sustentável em sua gestão. Por isso, fatores como inadimplência e evasão, profissionalização e autonomia dos gestores, sistema de contratação de professores e funcionários condizentes com a realidade organizacional e melhoria significativa da relação universidade-empresa, além de assegurar uma cultura avaliativa, tomam-se fatores-chave para sua sustentação. As alternativas para superar, de forma eficaz, esse quadro crítico apontam para a necessidade imperiosa de melhorar sua comunicação interna e externa e de implantar uma estrutura organizacional flexível.

Palavras-chave: Ensino superior; Gestão; Profissionalização de gestores universitários.

\section{Abstract}

Brazilian higher education is experiencing a very complicated situation because it is required to show quality, to grow and to have sustainable management. Therefore, factors such as defaultand school evasion, managers' capacity building and autonomy, system of contracting professors and administrative staff adequate to the organizational culture, and a significant improvement of the university-company relationship not only guarantee an evaluative culture but also become key-elements for its sustainability. The alternatives to effectively overcome such critical situation indicate the urge to improve both intemal and external communication and to implement a flexible organizational structure.

Keywords: Higher education; Management; Professionalism of higher education managers.

1 Doutor em Educação pela UNESP/Marília.Professor do Mestrado em Administração e Vicereitor da Universidade Salvador-UNIFACS. Endereço: Rua Dr. Hosannah de Oliveira, 156 ap. 501 Salvador Bahia 41815-215

E-mail gmarbackneto@uol.com.br 
"Não são os mais fortes da espécie que sobrevivem, nem os mais inteligentes, mas sim os que respondem melhor às mudanças".

CHARLES DARWIN

\section{Contexto do Xeque}

Há aproximadamente dez anos, desde que a profissionalização gerencial das IES passou a ser vista como imperativo para o crescimento, grandes modificações vêm sendo introduzidas neste âmbito.

Vários cursos de MBA's e de pós-graduação têm se voltado para a formação de gestores de ensino superior, de mestres e de doutores das mais diversas áreas do conhecimento, mas não versados na administrativa, cujo desafio é lidar competentemente com as peculiaridades do ensino, por si só já repleto de complexidades, sem falar dos novos formatos atualmente introduzidos.

As fronteiras da inovação, em face das pressões da economia globalizada, dificultam a conciliação entre a visibilidade e 0 atendimento aos novos padrões de qualidade necessários ao ensino superior, o que vem retardando mudanças urgentes nesta esfera.

Com o aumento do número de egressos do nível médio, vários empreendedores resolveram fazer do ensino um novo negócio, sem consciência de que este não é como os outros. Formar pessoas na atualidade é muito mais difícil do que antes e, sobretudo, radicalmente diferente de criar produtos de consumo. Para Reis (2003, p. 27),

o fomento da concorrência faz com que as IES's disputem os melhores docentes, os potenciais discentes, os programas de financiamento ao ensino, pesquisa e extensão, as parcerias, que viabilizam os estágios, o desenvolvimento comuns de projetos, o fortalecimento da imagem institucional e 0 mercado de empregos.

As pertinentes exigências institucionais nesta área vêm comprovando a impropriedade do funcionamento de muitas IES e a resposta incide sempre na incapacidade de pagamento dos "consumidores". Um dos obstáculos para se pensar a nova universidade, aquela dotada de tais recursos, é o fato de que todos eles requerem um grande investimento, principalmente financeiro, aliado à mudança cultural. Casper (1997, p. 44) acentua:

A história não assegura nenhum papel essencial ou eterno para a moderna universidade de pesquisa, e é necessário considerar o horizonte do seu desaparecimento. Não que se deva abraçar a perspectiva do seu desvaneci- 
mento, mas sim levar a sério a possibilidade de que a universidade, como está hoje constituída, não mantém o futuro sob nenhuma hipoteca. [...] eu defendo um pragmatismo institucional, pragmatismo que reconheça que o pensamento começa onde nos encontramos e que abole todos os álibis.

Nessa competição não há legislação regulamentar e atribui-se ao mercado a "mão invisível".

As opções, para aqueles que dispõem de poder aquisitivo, são inúmeras, principalmente para os que contam com melhor formação escolar. Os critérios de escolha variam desde os melhores cursos do país, segundo os resultados do ENC (provão), até o mais barato, pouco exigente, para o atendimento cartorial. Não faltam informações para a escolha, desde 0 anúncio de prévia contratação até o eficiente boca-a-boca.

Ainda que a oferta de ensino superior tenha crescido significativamente (média de um estabelecimento particular novo a cada dia), não se altera a taxa de escolaridade neste grau, das mais baixas da América Latina, e já é visível a "quebradeira" resultante da ausência de qualidade, ainda que muitos consigam fazer suas matrículas e deixem de pagar os meses subseqüentes.

\section{Xeque}

Pelas questões apresentadas acima, já estamos em xeque e a competência gerencial é uma das peças deste xadrez. Sem estratégia bem-estudada e definida, a jogada poderá levar à falência.

Neste jogo, a imagem institucional é um dos componentes e a gestão inadequada é uma das razões de sua depreciação.

Eis alguns dos desafios a serem enfrentados pelas IES particulares:

\section{a) Taxas de inadimplência e evasão}

Com o ingresso, cada dia maior, de alunos provenientes do ensino médio das classes $\mathrm{C}$ e $\mathrm{D}$, a relação entre o que as famílias ganham e o que devem pagar à IES gera déficit familiar. Arriscam a obtenção de uma bolsa e, enquanto aguardam, não pagam as mensalidades. Esta atitude compromete diretamente a gestão de uma IES particular, que é a verdadeira fonte dos recursos. Tal postura tem total respaldo do governo quando proíbe que 0 aluno matriculado não possa ser desligado do curso por falta de pagamento. Deste modo, só na matrícula do período seguinte a IES poderá - tentar recuperar o débito.

Um destes comprometimentos para a gerência é a impossibilidade de reajuste salarial dos docentes ou impontualidade no pagamento do salário, o 
que afeta diretamente a qualidade educacional. Há IES atrasando até dois meses de salários. Acrescente-se a obsolescência dos laboratórios, desatualização do acervo das bibliotecas e insuficiência de títulos para a quantidade de alunos usuários. Além de um número reduzido de funcionários que passam a comprometer o atendimento aos alunos e, assim, a qualidade dos serviços.

Em artigo de 15/10/2003 na revista Carta Capital, Athayde ressalta como subtítulo: "O aumento do número de estudantes com mensalidades em atraso obriga as universidades particulares a aprimorar a gestão". Logo na abertura, cita pesquisa realizada por Lobo e Associados, cuja coordenadora, Profa. Maria Beatriz, afirma: "[...] há uma relação direta entre a qualidade do ensino e a taxa de inadimplência. Nas IES que obtiveram conceitos A e B no Provão, a taxa é de $12,1 \%$, enquanto nas que obtiveram notas $\mathrm{D}$ e $\mathrm{E}$ a taxa praticamente dobra: $21,9 \%$. Nas que obtiveram nota C, a taxa é de $16 \%$." Mais adiante, o Prof. Roberto Lobo afirma que "as instituições de ensino superior que 'quebram' são as que apresentam problemas de gestão [...] uma das armadilhas para as IES privadas de ponta é tentar imitar o modelo das universidades públicas e se esquecer da realidade do setor". Tais observações comprovam a importância do gerenciamento profissional, quando ignora modismos ou modelos de instituições de outra natureza jurídica. Todavia, quanto ao primeiro aspecto relatado pela Profa. Maria Beatriz, sabe-se que há vários outras formas de avaliação, independentes do Provão, mais competentes como instrumento gerencial, pelo detalhamento que permitem.

Uma das formas de vencer obstáculos é a análise por curso, para observar nuances e flutuações de demanda. Como se sabe, há cursos que são procurados por um público de uma determinada renda, outros com nível mais baixo. O resultado mais importante dessa pesquisa salienta que "a qualidade vem influenciando decisões de alunos e, quando [há] bom aluno, ele exige respostas". Ao se referir ao acesso na classe C às IES privadas, o consultor Paulo Renato Souza, ex-ministro da Educação (2003), apud Faculdades (2004), observa que essa classe representará 60\% dos estudantes de ensino superior até o ano 2008. E acrescenta: "Será preciso oferecer um serviço mais adequado a essa classe, com custos mais baixos. O problema é que a eficiência nunca foi uma preocupação porque não havia competição no setor."

O financiamento do ensino superior - assunto polêmico há algumas décadas - vem sendo tratado por aproximadamente 17 projetos de lei que tramitam no Congresso. Entre eles, há desde propostas de uso do FGTS para pagamento de escolas privadas até o que propõe a cobrança de imposto de egressos de universidades públicas quando começarem a trabalhar.

Sobre as taxas de evasão, Ribeiro (2003, p. 43) adverte: 
Em face desse tema, são diversas as posturas. Se individualizamos demais o problema, culpamos o aluno que larga um curso por outro, chamando-o de irresponsável. Com freqüência é essa a atitude dos pais. Mas já não é essa a postura de qualquer administrador universitário sério, até porque ele, conhecendo as estatísticas, saberá que o problema tem abrangência bem maior que a eventual vagabundagem de um filho: fatores sociais podem ser identificados, que prevalecem, como elementos explicativos, sobre os individuais. Assim, uma posição mais respeitável consiste em ver qual problema está tendo aquele curso no qual ocorre maior evasão. Estarão as aulas sendo mal ministradas - faltarão equipamentos, desconhecerão os vestibulandos em que consiste aquela carreira? Diria eu que hoje é essa a atitude predominante na administração universitária, e tem muito de correto. 43) explica:

E, ao sublinhar o lado positivo da evasão, o próprio Ribeiro (2003, p.

A evasão pode constituir uma reação bastante saudável, não só em face dos defeitos acima expostos (aulas ruins, programa velho, ignorância de rumos), mas perante o próprio modelo de uma universidade baseada em formações definidas de uma vez por todas. Se há algo que envelheceu no mundo acadêmico é a idéia de que cada área deva estar fechada sobre si, e de que a melhor formação seria aquela em que o aprofundamento corresponda a uma delimitação cada vez mais estreita do terreno em que se cava o poço.

\section{b) Profissionalização e autonomia dos gestores}

Este é um grande desafio para as IES que têm mantenedoras com estrutura familiar e que se prolonga até as mantidas, fazendo com que os gestores de primeiro escalão nem sempre tenham autonomia nas decisões, dependentes sempre de conselhos, que burocratizam as decisões e reduzem a agilidade nos processos. Quanto à relação entre a autonomia, o planejamento e o orçamento com a gestão da universidade, Casper (1997, p. 64) assinala:

A autonomia da universidade em relação ao orçamento constitui um dado fundamental para a competição. O sistema universitário norte-americano perderia grande parte de seu dinamismo se os recursos financeiros não pudessem ser rapidamente aplicados nas áreas que originarão um maior "lucro" intelectual para a instituição. [...] Todos os níveis da administração, assim como os departamentos, devem favorecer esta flexibilidade. Ora, se apenas os altos escalões da universidade possuírem autonomia, a flexibilidade deixaria de existir.

Em momentos de grande competição, a necessidade de decisões rápidas é um fator diferencial para se enfrentar os "dinossauros". Outro fator que contribui para a lentidão das decisões é a estrutura organizacional basea- 
da em departamentos, verdadeiros feudos. À luz de reflexões assim, a universidade, por sua grande diversificação, poderia estar renovada. Entretanto, ela não se abre para esse horizonte devido à natureza obsessivo-compulsiva de seus ritos e à disputa pelo comando das atividades, sejam elas de pesquisa, ensino e extensão, além de não se praticar as formas avançadas de departamentalização. Apesar disso, algumas, principalmente as particulares, são mais ágeis porque os respectivos donos influem diretamente no seu destino.

O momento pede estruturas leves, com poucos níveis hierárquicos e gestores capacitados, dinâmicos. Para que se exerça tal autonomia, é preciso também que o mantenedor tenha confiança no gestor profissional. Há universidades em que o reitor nem sequer conhece o orçamento. Relaciona-se, ainda, à questão financeira a negligência dos que não conseguem interagir com outras áreas e assim reduzir custos, otimizar idéias e obter avanço na qualidade. Tais problemas vinculam-se a climas organizacionais adoecidos, também ligados à competência gerencial. Neste ponto, confirma-se que os gestores cada vez estão menos preparados para administrar com um clima sadio, não demagógico, mas sim, criando espaço para que as pessoas que trabalham na organização tenham interesse em prosseguir nas lutas institucionais. Sobre essas coalizões que devem passar a existir por necessidade dos gestores, Keeley apud Motta (1991, p. 57) observa:

[...] a ação cooperativa numa organização não requer que os participantes detenham objetivos coletivos. Muitas organizações possuem alto grau de dissenso sobre os objetivos e sobrevivem muito bem. $\mathrm{O}$ que mantém 0 sistema unido não é necessariamente a concordância sobre resultados da ação conjunta, mas a concordância sobre as próprias ações e os benefícios que cada participante obtém da ação.

O que já se observa é uma rotatividade grande de gestores que procuram, pelo menos, ser bem-remunerados, já que, no geral, o clima vem se assemelhando nas diversas IES. Considerando as demandas de mudanças na universidade e principalmente na sua gestão, Murphy (2000, p. 167) cita Handy (1990), para quem

as organizações do futuro serão caracterizadas pela cultura do consentimento. Organizações do consentimento terão estruturas achatadas e descentralizadas, onde tudo acontece pelo consentimento, não dando lugar ao jogo de comandar e controlar pessoas. [...] as pessoas inteligentes preferem concordar em vez de obedecer. Profissionais do futuro serão independentes e estimulados por idéias e ideais, procurarão organizações que respeitem essas qualidades e onde possam dar o melhor de si. 


\section{c) Sistema de contratação de professores e funcionários condi- zentes com a realidade organizacional}

A regularização prevista na Lei de Diretrizes e Bases da Educação Nacional (1996) trouxe imposições baseadas na gestão das IES públicas, sem as dificuldades das particulares no que tange à manutenção de docentes de tempo integral e com titulação. Atender ao artigo 52, ainda que se reconheça seu sentido qualitativo, mantendo $1 / 3$ de professores em tempo integral e 1/3 de professores com titulação de mestres e doutores, compromete a sobrevivência financeira - pois a maior parte das IES tem seus Planos de Classificação de Cargos e Salários baseados na titulação. Ainda que não necessariamente, isto enseje a elevação da qualidade acadêmica, cria a possibilidade de pesquisa e publicação. A contratação de muitos mestres e doutores, em tempo integral, tem obrigado algumas IES a reexaminar sua sustentabilidade. Há notícias de que muitos doutores, de áreas muito específicas, estão desempregados no Sul do país. Espera-se que um doutor seja profundo conhecedor de sua área, e que seja dotado também de outras habilidades e competências: versatilidade e possibilidades de trabalhar no ensino (graduação e pós), pesquisa e extensão, além de flexibilidade para ser um gestor. Tudo isso vale na luta pela sobrevivência. Mas, como conseguir alguém que seja bom em tudo?

Justifica-se o controle estatal da qualidade e, por isso mesmo, mais do que nunca a gestão deve ser criativa e inovadora na otimização dos recursos.

\section{d) Incrementar a relação universidade-empresa}

É preciso buscar diferentes parcerias com as empresas capazes de agregar valor ao papel da universidade. Não se trata de subjugar-se aos ditames do mercado, nem é necessário que as empresas planejem substituir internamente o papel da universidade. Seus papéis são complementares e o ganho é generalizado.

A empresa poderá contar com um serviço altamente técnico-especializado, com custos muitas vezes menores do que manter empregados contratados, e a universidade precisará obter os recursos necessários para trabalhar em prol da sociedade, e com espírito de vanguarda.

A criação das universidades corporativas, apesar de aparentar ser uma ameaça ao ensino universitário, ainda não é uma realidade. Muitas empresas as criaram obedecendo a mais um modismo; todavia, não têm idéia de como trabalhar corretamente.

Nos cursos seqüenciais de formação específica e nos de pós-graduação lato sensu a troca vem ocorrendo com um crescimento significativo, devido, principalmente, ao caráter pragmático e especializado desses cursos.

A esse respeito, escreve Marback Neto (2002, p. 233): 
As grandes organizações (principalmente as multinacionais) já estão começando a atuar na educação superior, com a justificativa de que os cidadãos formados pela universidade não mais atendem às suas necessidades. Deste modo se observam várias iniciativas de criação de universidades corporativas. O boom da criação dessas universidades aconteceu no ano 2000.

Atualmente, no Brasil, há cerca de 25 universidades corporativas, enquanto nos EUA, em 1999, já chegavam a 2.000. Deve-se, entretanto, observar que as universidades assim designadas visam somente aos objetivos organizacionais, atuam mais com treinamento e atualização de profissionais do que com formação humana. Assim, não são autorizadas pelo MEC e seus certificados ou diplomas, para a área de educação, não têm o mesmo valor que o das tradicionais. $\mathrm{O}$ problema é o uso da palavra universidade, que tem um outro significado para a sociedade, enquanto que, para as grandes empresas, 0 termo deve se aplicar à formação de mão-de-obra qualificada.

Eis, de acordo com Ribeiro (2003, p. 49), o que deveria competir mais à empresa do que à universidade:

[...] as empresas estão se tornando, ou podem se tomar, escola de um novo tipo. Antes de mais nada, são elas que ensinam rotinas e procedimentos. Essa tradução do macro em micro, da teoria em prática, dos princípios aprendidos em atuação, é bom que não seja feita na universidade, mas na empresa. Por uma razão bastante simples: é isso o que mais varia.[...]É melhorque, em seus anos de formação, o jovem lide com o que terá permanência e, com isso, lhe dará uma base sólida, do que com detalhes em constante mudança.

\section{e) Assegurar uma cultura avaliativa}

A avaliação institucional é um poderoso e imprescindível instrumento gerencial e pedagógico que envolve aferição, revisão e construção. Além disso, revela a adequação e a qualidade do desempenho institucional, com base em critérios, gerando insumos para os processos de tomadas de decisões e implantação de resultados. Numa visão complementar, Morosini e Leite (1997, p. 143) assinalam que a avaliação "é vista prioritariamente como um ponto de partida para as mudanças necessárias na instituição e no próprio sistema educacional. Ela é um 'organizador' das idéias dispersas e fragmentadas sobre os males que afligem a instituição".

Avaliação institucional é ainda o processo global em que se revisa o que foi planejado e se constrói, continuamente, a universidade, mediante o processo de autoconhecimento. Nessa revisão contínua, deve-se considerar principalmente a missão da universidade e o contexto em que se situa, bem como sua história. Por isso, o essencial não é haver um modelo único de avaliação, e sim que esta seja adequada, sempre, à identidade de cada instituição. A avaliação é um processo que não pode resolver, imedi- 
atamente, os problemas macroestruturais, embora possa contribuir para mostrar essa perspectiva.

No Brasil, seus primeiros passos foram dados na década de 1980 e, principalmente, depois de 1995, com a criação do PAIUb (Programa de Avaliação Institucional das Universidades Brasileiras). O problema é que os gestores não entenderam o objetivo maior desse instrumento que, sem dúvida, pode ser a grande mola propulsora para a melhoria da gestão universitária. Muitos acreditam em seu valor para a área acadêmica, outros, para a área administrativa. Só não conseguiram entender que este pode ser um recurso para manter o equilíbrio da IES entre a oferta e a procura, além de ser uma grande ferramenta gerencial. Uma das dificuldades das IES, que adotaram este processo, é a falta de respostas à comunidade acadêmica quanto a seus resultados. Na maioria das vezes, cumpriram uma formalidade legal. Há vários casos em que o processo não agrega espontaneamente e descaracteriza-se pela falta de democracia.

Como perda também dos resultados dos processos de avaliação, ainda há o exemplo de algumas IES que, mesmo com este instrumento em mãos, preferem contratar empresas de consultoria para trabalhar o clima organizacional e efetuar pesquisas de mercado. Não conseguem, sequer, citar os dados da avaliação. Isso comprova a falta de creditação que é dada à atividade e aos instrumentos de avaliação elaborados pela própria comunidade. Outras, ainda que tirem algum proveito dela, não lhe creditam as decisões, contribuindo para a descrença da comunidade acadêmica quanto ao processo.

Com estes entraves à implantação efetiva da avaliação institucional nas IES, o Estado brasileiro assegura a formalidade e eleva o descrédito. Se nas IES públicas o problema de implantar resultados está principalmente na falta de recursos financeiros, nas particulares, falta vontade política e consciência de seu papel. Como entende Marback Neto (2002, p. 292), eis o que se deve considerar:

A contribuição do processo de avaliação institucional para o processo de tomada de decisões na universidade, independentemente do modelo adotado (Baldridge \& Birmbaum), é permanente e inconteste, pois sempre haverá uma via mão dupla da qual todos participam e onde vêem os destinos de suas demandas. A avaliação é uma forma também de legitimar as decisões nas universidades. Isto, num tempo de escassez de recursos, torna-se interessante para os gestores que dividem com os demais atores o poder de definir prioridades.

Uma atividade importante para a implantação da cultura avaliativa é a comunicação na universidade. Esta área ainda é bastante rudimentar nas IES justamente pela pouca importância que se dá a ela. Quanto a esse aspecto, Ribeiro (2003, p. 65) mostra o que é crucial: 
[...] as comunicações internas no mundo acadêmico também são ruins. Falase pouco, trocam-se poucas idéias. A maioria esmagadora dos órgãos de divulgação universitários - jornais, rádios, TVs - evita tratar de questões delicadas, por exemplo, dos conflitos internos. [...] Não se deve considerar a comunicação enquanto mero instrumento. Não está em questão divulgar melhor, com mais brilho, de maneira mais agradável, as ações universitárias. [...] O que está em jogo é bem mais do que isso: é uma concepção da universidade na qual o diálogo é raro e ralo.

A avaliação institucional é imprescindível porque, quando bem-executada, fecha o círculo da gestão, constitui seu princípio e fim. O princípio concerne ao diagnóstico da situação, que é valioso para o planejamento institucional, atualmente denominada PDI (Plano de Desenvolvimento Institucional). Como fim, ela é um instrumento que pode, com base no planejamento, abalizar os resultados da instituição, para que se possa observar a eficiência e a eficácia organizacional, aspectos essenciais à consecução da meta de qualidade desejada.

O grande entrave ao maior desenvolvimento da avaliação institucional nas universidades é o tratamento dos resultados do processo. Para Paul, Ribeiro e Pilatti (1990, p. 17), o primeiro deles é a aparente ausência de um processo de decisão nas unidades envolvidas. Nada se faz com os dados coletados. Algumas vezes, por falta de recursos; outras, por falta de iniciativa dos atores para buscar soluções para os problemas identificados. Há um certo receio de divulgar resultados, principalmente quando não são bons, pois 0 ranking efetuado pela mídia já desgasta bastante o processo. Nesse aspecto, há momentos da universidade que, por causa do clima organizacional, são inadequados para a divulgação de resultados. Geralmente isso ocorre no final de cada perío do letivo, quando os atores estão mais estressados e mais vulneráveis a qualquer crítica.

\section{Como NÃO entrar em xeque-MATE}

Implementar um programa de comunicação constante, abandonando a prática da propaganda somente na época do processo seletivo. Até o mais ingênuo eleitor condena os políticos de ocasião. A sociedade atual exige das universidades, públicas ou privadas, a transparência gerencial efetiva. Só assim se diferenciarão. Esta é uma das importantes formas de atrair e manter alunos e professores.

É imperioso manter um relacionamento aberto e elucidativo com 0 público interno (professores, funcionários e alunos). Não subestimar jamais a inteligência de seus parceiros de realização. 
Implantar uma estrutura organizacional que permita flexibilidade aos gestores, fazendo com que a interdependência dos setores seja um diferencial acadêmico e administrativo, pois irá fornecer uma noção sistêmica e mais abrangente da instituição.

Preservar a imagem positiva junto à sociedade somente a partir de estratégias de marketing, sem preocupar-se com a comunicação contínua, em nada contribui para o aumento de condições competitivas para a IES. A manutenção de um saudável clima interno tem na transparência das atitudes seu fator primordial. A instalação da cultura do medo e do erro é sempre um entrave para o trabalho profissional e competente. Como internalizar normas e procedimentos mal definidos? E como gerenciar grupos que não vivem as normas? A centralização das decisões e a falta de transparência e de relacionamento aberto entre funcionários, professores e dirigentes são responsáveis pela deterioração do clima organizacional.

Criar um trabalho diferenciado para os públicos internos, proporcionando novas formas de relacionamento, é outro grande desafio para o gestor.

Assim, será possível formar pessoas para o pleno exercício da cidadania neste país, o qual precisa conquistar a dignidade de seu destino histórico - pessoas em sintonia com seu tempo e capazes de projetar um futuro; e, de modo concomitante, formar profissionais competentes, ágeis e empreendedores. Assim, poderá ser digno desse nome o ensino superior no Brasil. Entretanto, cumpre ressaltar, essas condições de possibilidade nunca poderão ser obtidas com amadorismo na gestão.

O conhecimento administrativo constitui a grande estratégia para a seriedade desta tarefa, que é urgente.

\section{Referências}

ATHAYDE, P. A pressão da inadimplência: o aumento do número de estudantes com mensalidades em atraso obriga as universidades particulares a aprimorar a gestão. v. 10, n. 262, 2003. Disponível em: <www.http:// cartacapital.terra.com.br/site/index_frame.php>. Acesso em: 2 mar. 2004.

CASPER, G. et al. Um mundo sem universidades? Organização e Tradução de Johannes Kretschmer; João Cezar de Castro Rocha. Rio de Janeiro, RJ: UERJ. 1997.

FACULDADES se adaptam a público de classe C. Folha de São Paulo, São Paulo, 03 ago. 2003. Disponível em: <www1.folha.uol.com.br/fsp/cotidian/ ff0308200302.htm>. Acesso em: 26 fev. 2004. 
MOTTA, P. Gestão contemporânea: a ciência e a arte de ser dirigente. Rio de Janeiro, RJ: Record, 1991.

MARBACK Neto, G. A avaliação institucional como instrumento de gestão universitária. 2001. Tese (Doutorado em Educação) - Universidade Estadual Paulista, São Paulo, SP: 2001.

MOROSINI, M; LEITE, D. Avaliação institucional como um organizador qualificado: na prática é possível repensar a universidade? In: SGUISSARDI, V. (Org.). Avaliação universitária em questão: reformas do Estado e da educação superior. São Paulo, SP: Autores Associados, 1997. p. 123-148. (Coleção educação contemporânea).

MURPHY JR, P. Administração do ensino superior numa nova era: os rápidos e os mortos. In: MEYER JR, Victor; MURPHY, Patrick. (Org.). Dinossauros, gazelas e tigres: novas abordagens da administração universitária. Santa Catarina: Insular, 2000. p. 159-171.

PAUL, R; et al. O. As iniciativas e as experiências de avaliação do ensino superior: balanço crítico. In: DURHAM, E.; SCHWARTZMAN, S. Avaliação do ensino superior. São Paulo, SP: EDUSP. 1992. p. 141-167.

REIS, F. Perspectivas da gestão universitária. Taubaté: Cabral, 2003.

RIBEIRO, R. A universidade e a vida atual: Fellini não via filmes. Rio de Janeiro, RJ: Campus, 2003.

Recebido em: 10/02/2003.

Aprovado em: 20/06/2005. 